University of Nebraska - Lincoln

DigitalCommons@University of Nebraska - Lincoln

Publications from USDA-ARS / UNL Faculty

U.S. Department of Agriculture: Agricultural

Research Service, Lincoln, Nebraska

2005

Risk and ethics in biological control

Ernest S. Delfosse

United States Department of Agriculture

Follow this and additional works at: https://digitalcommons.unl.edu/usdaarsfacpub

Part of the Agricultural Science Commons

Delfosse, Ernest S., "Risk and ethics in biological control" (2005). Publications from USDA-ARS / UNL Faculty. 411.

https://digitalcommons.unl.edu/usdaarsfacpub/411

This Article is brought to you for free and open access by the U.S. Department of Agriculture: Agricultural Research Service, Lincoln, Nebraska at DigitalCommons@University of Nebraska - Lincoln. It has been accepted for inclusion in Publications from USDA-ARS / UNL Faculty by an authorized administrator of DigitalCommons@University of Nebraska - Lincoln. 


\title{
Risk and ethics in biological control
}

\author{
Ernest S. Delfosse* \\ National Program Leader for Weed Science, U.S. Department of Agriculture, Agricultural Research Service, \\ National Program Staff 5601 Sunnyside Avenue, Beltsville, MD 20705-5139, USA \\ Received 9 January 2005; accepted 14 September 2005 \\ Available online 2 November 2005
}

\begin{abstract}
All introduced natural enemies present a degree of risk to nontarget species. Since most biological control programs use relatively host-specific natural enemies, the risk to nontarget species is generally very low, particularly from biological control of weeds, which uses extensively tested and validated host-specificity testing procedures to predict risk. However, many of the published comments about risks of biological control are superficial or misleading, often inappropriately lumping risk from all taxa of agents as "the risk of biological control," and ignore the potential benefits, rather than dealing with species-by-species risk and benefits. Particularly confounding accurate predictions is the common mixing of parameters of hazard and exposure in discussions of risk. In this paper, traditional risk analysis techniques are discussed and adapted for biological control. How people perceive risk is the key to understanding their attitude to risk. Some of the criticisms of biological control relating to inadequate post-release monitoring are valid and the ethical responsibilities of biological control scientists in this area are also discussed. Biological control scientists should address objectively the criticisms of biological control, continue to review and adjust current host-specificity testing procedures and make appropriate changes. This process will result in better science, ultimately delivering more focused programs, and altering the perception of risk from biological control agents by objective observers.

Published by Elsevier Inc.
\end{abstract}

Keywords: Biological control; Risk analysis; Hazard; Exposure; Risk perception; Risk assessment; Ethics

\section{Introduction}

In this paper, I examine risk and ethics in biological control, to demonstrate the social responsibility of scientists who have been trained in biological control. Increased focus on these issues can be used to expand biological control research, to document programs more completely, and to communicate results of the programs more widely.

Biological control is a pest management tactic that utilizes deliberate introduction of living natural enemies to lower the population level of invasive pests (DeBach, 1974; DeBach and Rosen, 1991; Huffaker and Messenger, 1976; Van Driesche and Bellows, 1996). Biological control is not a panacea and is not risk-free (Delfosse, 2000). There are

\footnotetext{
* Fax: +1 3015046191.

E-mail address: esd@ars.usda.gov.
}

pest management needs and situations where, clearly, another strategy is more appropriate or should have higher priority. For example, if a new, potentially invasive pest is found in a localized area, the appropriate strategy is eradication with pesticides. Also, biological control is a strategic process with limited use in emergency pest control programs. However, for widely established pests, or for those with the potential to become widespread but are at an early stage of invasion (but beyond the point of eradication), biological control is often the most appropriate strategy.

Every biological control agent that has ever been used has associated risk. The quantification of that risk is a very challenging and difficult activity, which has been the subject of extensive research and discussion (Andersen et al., 2005; Lonsdale et al., 2001; McFadyen, 1998; Wapshere et al., 1989; Waterhouse, 1999; Wright et al., 2005). In fact, the history of biological control has seen an evolution from no testing of agents, to testing important crops in a region, to 
selecting test plant species based on a scientific centrifugal phylogenetic testing procedure, to focusing on relatedness and physiological and ecological host range. However, many of the published discussions about biological control risk do not seem to be informed by knowledge of this history, or of the biological control process. Often, discussions have been superficial or misleading; a common error is to talk about "the risk from using biological control," grouping risk from all agent taxa. Additionally, the potential benefits of biological control should be discussed. If not, the analysis can be misleading, because ignoring environmental and economic benefits of biological control is clearly as unreasonable as ignoring associated risks. Decisions to implement biological control should be made in as full a context of benefits and risks as is available (Jetter, 2005; Sheppard et al., 2003). Thus, I lead off with a general discussion of risk analysis, which I refine for use with biological control agents.

A highly developed sense of environmental ethics has always been inherent in how biological control ecologists operate, but until recently, has been rarely discussed outside of scientific meetings. Thus, of many possible topics in this area, I discuss, unanticipated consequences, conflict-ofinterest, post-release monitoring, and the do-nothing option. Finally, release of Rhinocyllus conicus Frölich (Coleoptera: Curculionidae) against nodding thistle (Carduus nutans L.; Asteraceae) is discussed as a case history, because it is used by different groups and individuals either as an example of a well-planned and conducted program, or one where risk to nontarget species was not adequately considered before release.

\section{Risk and biological control}

Risk is a relative concept used to imply uncertainty, and estimates and perceptions of risk change as knowledge improves. Risk can be expressed as the interaction between hazard and exposure (Davis, 1996; Molak, 1997a; NAS, 1983). A conclusion that an adverse effect has occurred or could occur (see below) that is the basis of a perception of risk is a highly subjective value judgment. Importantly, the perception of risk is not necessarily in proportion to the actual risk; in fact, for risk in general, the perception is often higher than the reality. Risk is therefore often used when uncertainty can be quantified to some degree. When there is uncertainty about whether a hazard exists, there is a probability at some level that it does exist, presenting a risk (Wilson and Shlyakhter, 1997; Wilson et al., 1985). It is the role of the risk assessor to quantify this risk and estimate the imprecision. An uncertain risk suggests a paradox and a contradiction (Wilson and Shlyakhter, 1997) in cases where the existence of a hazard has not been established. This is often the case in biological control.

Acceptable risk is used when uncertainty is quantified to the subjective satisfaction of a viewer. Uncertainty is measured by the deviation from expected values which are also subjective and difficult to quantify. Thus, when probabili- ties of different outcomes are unknown, uncertainty is transformed into risk, where probabilities of outcomes are weighted according to their likelihood of occurrence.

Irreversible actions and option value are important to consider when evaluating risk in a biological control program. An irreversible action is one that limits future options. Option value arises from retaining an option to a good or service (including, for example, both the target species and potential nontarget species) for which future demand is uncertain. Option value could be compromised if biological control of a target species is successful, and if a use for the species is developed subsequently (e.g., the development of a weed as a herbal product, or the loss of floral beauty in a landscape, albeit by an invasive weed, which may be unknown to a casual observer). Option value is also affected by the risk premium, the amount people would be willing to pay to avoid the risk of not having something (such as the nontarget species) available to them which they may want in the future (over the expected value to them). Quasi-option value measures expected value of future information; i.e., benefits of delaying a decision when an alternative involves an irreversible action (such as biological control agent introduction) and there is uncertainty about the future benefits of alternatives (such as for use in habitat conservation, commercially, endangered species restoration, etc.).

In general, the greater the potential benefits, the greater the acceptable risk, as long as the benefits are not available through another activity that poses less risk (Swaney, 1997). This is a key point in deciding which integrated pest management (IPM) strategy to use, including biological control. Thus, in any predecision analysis, it is important to estimate potential benefits of using a strategy as well as the potential risks.

\subsection{Risk analysis}

Risk analysis is a tool, and like other areas of science, has limitations when dealing with "essentially complex phenomena" (Hayek, 1991). Risk analysis is comprised of risk assessment, risk management and risk communication (Ahl et al., 1993). Molak (1997a) is an excellent resource for risk analysis procedures and examples. Risk analysis should be a transparent public process, with all assumptions and parameters clearly stated (MacDiarmid, 1997; Molak, 1997b). I agree with the statement that "The thought process that goes into evaluating a particular hazard is more important than the application of some sophisticated mathematical technique or formula, which may often be based on erroneous assumptions or models of the world" (Molak, 1997b).

In risk analysis, probabilities of possible outcomes are estimated (Molak, 1997a). For biological control, the adverse effect is damage (anticipated or not) to a nontarget species from a biological control agent. Understanding the nature of this damage is the key, and there is a continuum of type, extent, temporal, and spatial aspects of damage 
that must be considered (Delfosse et al., 1995; Hasan et al., 1992).

For example, exploratory nibbling by an arthropod, or development of a few tiny sori of a rust fungus on a leaf, producing a small number of nonviable spores are, arguably, "adverse effects," but have no measurable negative population effects on the nontarget species, and do not place that population at significant risk. Transitory damage by a biological control agent on a nontarget species that is in the agent's physiological host range also does not present a significant risk to the nontarget species (Delfosse, 2004). Such transitory damage only occurs during the exponential growth phase of the agent, but disappears once the agent and its target reach equilibrium. This emphasizes the essential value of host-specificity testing at identifying cases of likely transitory damage as part of a risk analysis for a biological control agent.

Risk analysis is a "body of knowledge (methodology) that evaluates and derives a probability of an adverse effect of an agent (chemical, physical, or other), industrial process, technology, or natural process" (Molak, 1997b). Most practitioners believe that risk assessment should be separate from risk management (Ruckleshaus, 1985; Sutter, 1993). Risk communication to the nontechnical community is often the most ignored step in the process (see below).

Analysis of risk from biological control is an example of an ecological risk analysis (Lackey, 1997). As Lackey (1997) points out, a "formidable problem ... is selecting what ecological component or system is to be considered at risk. This selection is entirely social and political, but estimating the actual risk is technical and scientific." The selection of what is potentially at risk can be somewhat less complicated in biological control, because biological control scientists have always concentrated on trying to predict the risk to nontarget species (including potential indirect risks to species which rely on the nontarget species). However, the estimation and acceptance of the risk can be enormously complicated, as with biological control of saltcedar (Tamarix spp., Tamaricaceae) in the United States (DeLoach et al., 2000).

NAS (1983) identified four common elements in risk analysis: (1) hazard (agent) identification; (2) doseresponse; (3) exposure analysis; and (4) risk characterization. In the risk characterization phase, data from the three previous steps are analyzed, assumptions are stated, and calculations and conclusions are made.

Recommendations for risk management and risk communication can then often be made. The NAS (1983) procedure deals essentially with human exposure to toxic substances, which is, of course, generally inappropriate for biological control (the major exception being the possibility of the rearing process of some augmentative biological control agent possibly producing airborne hairs or scales which are potential allergens). Thus, I suggest the following modifications of the NAS (1983) process to deal specifically with risk analysis of biological control agents:

\subsubsection{Hazard identification}

For biological control, I have defined hazard as the innate capacity of a biological control agent to cause harm (Delfosse, 2003); i.e., potential damage to nontarget species. There are important questions to ask in this context. Does the biological control agent cause the adverse effect? Is causality demonstrated (see below)? What else could cause or contribute to the adverse effect? Just because we are dealing with complex ecological systems and some type and level of harm to a population of a nontarget species occurs after the release of a biological control agent does not mean that harm was caused by the biological control agent.

\subsubsection{Dose-response relationship}

What is the relationship between the population level and incidence of a biological control agent and the adverse effect? Is nontarget damage a transitory effect that was predicted from host-specificity testing and is likely to disappear once a future equilibrium is reached? Are there data available that indicate something else?

\subsubsection{Exposure analysis}

What current or future exposures are anticipated in all habitats where the host or potential nontarget species occur? What phenological, temporal, spatial, edaphic, climatological, or other features may mediate exposure?

\subsubsection{Risk characterization}

Given the information from the first three points in the risk analysis process, what is the estimated incidence of the adverse effect in a given population? What other information is needed? Does the physiological host range determined by host-specificity testing predict accurately the ecological host range?

\subsection{Risk assessment}

Risk assessment is "risk analysis applied in a particular situation" (Molak, 1997b). The U.S. Environmental Protection Agency (EPA) (1992) defines ecological risk assessment as "the process that evaluates the likelihood that adverse ecological effects are occurring, or may occur, as a result of exposure to one or more stressors." Given the complexity of ecological systems, it is not an easy matter to adapt risk assessment techniques to ecological systems (Lackey, 1994) such as biological control, and some researchers do not accept that risk assessment should even be used (Merrell and Van Strumm, 1990). However, "use of risk assessment to help solve ecological problems is widely supported" (Lackey, 1997). Environmental risk assessments can be qualitative ("low," "medium," or "high") or quantitative (e.g., "a probability of 0.001 " for a given parameter). For biological control, risk assessment examines primarily the potential adverse effects of the introduction of a biological control agent on nontarget species, but can be expanded to include other aspects of the environment. Closely linked to risk assess- 
ment, of course, are global regulatory policies and procedures that can facilitate (the facilitator model) or impede (the gatekeeper model) an unbiased review and rapid approval of sufficiently host-specific natural enemies (Barratt and Moeed, 2005; Delfosse, 2004; Sheppard et al., 2003).

\subsection{Risk management}

Risk management identifies and implements strategies to reduce risk to an acceptable level. The "mitigation" clauses that are sometimes included in regulatory protocols are essentially risk management tools. Currently the emphasis by regulatory bodies dealing with classical biological control in the United States is primarily on risk assessment, not risk management or risk communication (e.g., APHIS, 2000; AQIS, 2000; NAPPO, 2000).

\subsection{Risk communication}

Objective communication of risk to the general public is the least-developed part of the risk analysis process for biological control. Biological control scientists communicate the risks of biological control very well to colleagues through publications, scientific and public meetings, etc., and to regulatory officials through permits for importation and release of agents, but not very well in general to the public. The benefits of biological control are almost never mentioned in this context; thus there is a bias in favor of perceived risk that can be higher than actual risk. This should be of considerable concern to biological control scientists and beneficiaries of research on biological control, because often biological control is the best available strategy to manage an invasive pest - sometimes the only sustainable and affordable strategy (Delfosse, 2000).

Unfortunately, generalizations about biological control risk have emerged, and can temporarily outweigh over 130 years of mostly safe and effective biological control. Scientists trained in biological control find it frustrating that it is the negative aspects of biological control that are communicated and receive the most widespread attention (Gagné and Howarth, 1985; Hamilton, 2000; Howarth, 1983, 1985, 1991; Louda et al., 1997; Miller and Aplet, 1993; Simberloff, 1992; Simberloff and Stiling, 1996; Stolzenburg, 1999; Strong, 1997; Zimmerman, 1958, 1978). Sometimes, this information is incomplete (benefits are glossed over or ignored, the literature cited is selective, perceived risk is stressed, biological control process not articulated clearly, etc.), inaccurate (perceived risk from a specific natural enemy is extrapolated to risk from all biological control), or based on anecdotal information and speculations from limited data. This is difficult to counter, but scientists trained in biological control need to take the lead to discuss objectively the benefits of biological control, as well as the risks, and the careful process that is followed (e.g., Lonsdale et al., 2001; Sheppard et al., 2003).

\subsection{Other useful analyses}

Several other techniques are available for risk analysis that are of fundamental importance to biological control, many of which incorporate benefit analysis. However, a detailed discussion of these techniques is beyond the scope of this paper, so readers are directed to Bier (1997), Lackey (1997), Swaney (1997), and Vose (1997) for a review of some techniques. The following techniques are some of the options.

\subsubsection{Probabilistic risk analysis}

Probabilistic risk analysis (PRA) (Bier, 1997) has particular applications for biological control. PRA asks three basic questions (Kaplan and Garrick, 1981): (1) what can go wrong (a hazard identification)?; (2) how likely is it to go wrong (a likelihood identification)?; and (3) what will be the consequences if it does (a consequences identification)?

\subsubsection{Risk-benefit analysis}

Risk-benefit analysis (RBA) is well established in both policy [the U.S. Food and Drug Administration uses RBA "when it expedites the approval of drugs for critical care circumstances;" (Swaney, 1997)], and law [the Toxic Substances Control Act requires the EPA to consider benefits and risks of chemicals (Callan and Thomas, 1996)]. The Federal Insecticide, Fungicide, and Rodenticide Act requires EPA to regulate pesticides on a risk-benefit standard, balancing "the economic, social, and environmental costs, as well as the potential benefits of the use of any pesticide."

\subsubsection{Comparative risk analysis}

Comparative risk analysis (CRA) ranks risks for the magnitude of the threats they pose to ecosystems (or to another factor), helps identify undermanaged risks, and combines expert and public opinion.

\subsubsection{Benefit-cost analysis}

Benefit-cost analysis (BCA) produces a "present-value" measure of the net benefits of a proposed action, such as release of a biological control agent, and when combined with sensitivity analysis, produces a range of net-benefit values useful in determining the impact of discount rates on estimation of net benefits. However, BCA results in a single number that doesn't indicate the degree of uncertainty, the range of expected values, or attitude toward risk. The past trends of biological control, indicating an overwhelmingly safe record (Waterhouse, 1999) could be useful in BCA.

\subsubsection{Sensitivity analysis}

Sensitivity analysis can also be used to address risk and uncertainty. Effects of different assumptions about key variables are examined. In sensitivity analysis, optimistic and pessimistic values indicate which variables will have greatest effects on benefits and costs. This procedure yields crucial variables, not probabilities. Each potential outcome is weighted by its probability of occurrence (by past trends, 
subjective judgments, experimentation, etc.); and the weighted outcomes are summed to arrive at a mean, or expected, value.

\subsubsection{Cost-effectiveness analysis}

Cost-effectiveness analysis (CEA) helps identify "the least costly route to the specified goal" (Swaney, 1997). Such a goal could be, for example, management of an invasive pest species. These economic analyses deal with opportunity cost, the value of the next-best use of a resource measured as foregone alternative benefits (Swaney, 1997). CEA has not yet been employed in biological control, but offers potentially a useful way to quantify the economic benefits of biological control.

\subsection{Causality}

Causality should be examined critically and objectively when assessing the risk from biological control. For example, too often the glib statement, "absence of evidence is not evidence of absence" is sometimes used uncritically in spite of the total lack of supporting facts. The statement has been applied to biological control (and to other fields, e.g., Anderson, 2004). It could equally be said by those who want to believe that there are no or minimal effects from release of biological control agents that "absence of evidence is not evidence of presence." However, these types of emotive statements should be avoided, because they add nothing to the positive discussion that is emerging by the majority of scientists who want to find out what is actually happening in the field, and to use the data to improve the biological control process.

The U.S. EPA (1989), Gibb (1991), and Rothman (1986) provided causality guidelines for dealing with cancer risk assessment, which I have modified to deal with biological control. In this process, care must be taken to avoid post hoc ergo prompter hoc (after this, because of this), a common logical fallacy (Hardin, 1998).

\subsubsection{Compounding}

Could the adverse effect be a result of compounding, which is attributing the adverse effect to one study variable, when the true cause is another variable ("absence of evidence ...")?

\subsubsection{Bias}

Was bias present, for example in the way data were obtained or evaluated (Smith, 1995)?

\subsubsection{Statistics}

Was the analysis appropriate and complete, and was a description of the methods provided?

\subsubsection{Temporal and spatial relationships}

Was the biological control agent in the field at specific sites for a sufficiently long period to have developed a population level high enough to cause the alleged adverse effect? Is the effect transitory, and if so, is this an acceptable risk to the nontarget species?

\subsubsection{Consistency}

Did the same adverse effect occur at multiple sites? If not, what features of the site(s) where the adverse effect is alleged to occur contributed to the result? Will this occur into the future, or is the adverse effect likely to be transitional?

\subsubsection{Magnitude of adverse effect}

Causality is more credible when the risk is large and precise. Is the perceived adverse effect from a biological control agent limited to factors such as insignificant nibbling by a phytophagous arthropod that presents no population-level impacts to a nontarget species, or does it involve significant, long-term, population-level impacts on reproduction, survival, etc., of a nontarget species?

\subsubsection{Specificity of the association}

Most biological control agents are specific to a target organism, or to a small group of closely related organisms. If the adverse effect is alleged to occur on a distantly related species, the situation should be examined particularly carefully. Has causality been established ("absence of evidence ...”)?

\subsubsection{Biological plausibility}

Does the association of agent and perceived adverse effect make biological sense with respect to phenology, ecology, physiology, temporal, and spatial distribution, edaphic characteristics, weather, metabolism of target, and nontarget species, etc.?

\subsubsection{Coherence}

Are cause and effect in logical agreement with everything known about the agent, the target, and the system in which the adverse effect is alleged to occur? How does personal bias, both by pro- and anti-biological control advocates, affect coherence?

\subsection{The nature of risk from biological control}

Release of a classical biological control agent is a type of irreversible action; if the agent becomes established, it is unlikely to be able to be recalled. A biological control agent could limit the option value of the target species and of any nontarget species that are in its ecological host range. Thus, assessment of the potential risk from biological control is not simple, and oversimplification can lead to erroneous conclusions. The crucial variable of risk (and most fears) in biological control is measured by assumption of potential damage to valued nontarget species.

The damage to a nontarget species could be direct, for example, feeding by a biological control agent on a valued native plant (Louda et al., 1997), or indirect, by assumption of loss of a resource if biological control is successful, such 
as loss of pollen of a plant that is a weed to part of society and a valued resource to another, as in the Echium plantagineum L. (Boraginaceae) situation in Australia (Cullen and Delfosse, 1985; Delfosse, 1990; Wapshere et al., 1989). However, it is difficult to isolate the exclusive impact of potential risk by agents on nontarget species ("absence of evidence ..."). Environmental factors other than natural enemies influence risk, and if omitted, bias estimates of risk due to biological control ("after this, because of this"). When determining the risk to a nontarget species from a biological control agent, several other factors come into play.

First, generalizations about "the risk from biological control" are meaningless and misleading. It is always incorrect to lump risk from different taxa, trophic levels, etc., of biological control agents and to present this imaginary figure as "the risk from biological control." Clearly, a polyphagous predator does not present the same risk to nontarget species as a macrocyclic, autoecious rust fungus. Unless specific information on the agent and target is available and used from a known site, the variability becomes part of all the other uncertainties of a risk calculation.

Second, prior information can be useful in starting a risk assessment for a new biological control agent. For example, what is the level of specificity displayed by other members of the genus? Have other members of the same genus been used without causing nontarget damage? What is the nature of the nontarget damage that is produced-from nibbling on leaves of a target plant without oviposition, to heavy feeding, oviposition, and complete development similar to that on the target species? Is the damage transitory? Uncertainty diminishes with information gathered from research.

Third, expert judgment can help to estimate uncertainties in some cases (e.g., Evans et al., 1994a,b; Lackey, 1997), but "must be used with caution because experts are often overconfident" (Wilson and Shlyakhter, 1997; see also Henrion and Fischoff, 1986; Morgan and Henrion, 1990; Cooke, 1991). The perception of uncertainty can even increase as more research is conducted on a given subject (Morgan et al., 1984; Morgan and Keith, 1995), possibly because the probability judgments are attached to descriptions of events, not to the events themselves (Tversky and Koehler, 1994). This is clearly the case with biological control; the more that is known about a potential biological control agent, the higher the regulatory burden.

Finally, adverse effects are of course, often, subjective (Molak, 1997b), and determined by society. However, as with the Rhinocyllus-Cirsium example below, society's interpretation of adverse effects is not necessarily consistent over time or space, or with different groups of stakeholders. Behavior leading to conflicts-of-interest in choice of targets and agents is key to understanding the perceived value of potential adverse effects (Cullen and Delfosse, 1985; Pemberton, 2002). The potential benefits of biological control are often lost in this context, which also bias objective decisions, so it is important to conduct a $B C A$ along with the risk assessment. Unfortunately, economists and sociologists are not often available to conduct a BCA.

\section{Ethics and biological control}

The ethics of biological control scientists has been challenged by some critics of biological control. Occasionally, moralistic, relativistic, motivational, or situational ethics is used, where emotion-laden terms are employed for rejection of an action such as releasing a biological control agent, often looking to the past. What is needed is, of course, consequentialist ethics, where all reasonable alternatives are listed, and an observer chooses objectively among them, and comparing consequences of actions, looking to the future (Hardin, 1998).

Ethics of biological control have not often been explicitly discussed in the scientific literature. One exception is presented in a Special Issue of Agriculture and Human Values. In this volume, Lockwood (1997) proposed major ethical questions dealing with regulation and implementation of biological control "in the face of persistent ecological uncertainty regarding environmental impacts;" balancing benefits and risks; development of policies and decisionmaking; sharing benefits and costs of biological control; and justification for biological control as a replacement for pesticides or as part of a "reconceptualization of agricultural production." Even though the point about "persistent ecological uncertainty regarding environmental impacts" could certainly be challenged, and few biological control scientists would regard biological control as simply a replacement for pesticides, the volume raises important issues. Discussions of host-specificity testing (Van Driesche and Hoddle, 1997); environmental impacts of biological control in Hawaii (Duan and Messing, 1997); genetically engineered plants (James, 1997); assessment of fungal agents (Ricard and Ricard, 1997); institutional obstacles (Jennings, 1997); the decision-making process (Wilkinson and Fitzgerald, 1997); implementation in Central America (Bentley and O'Neil, 1997) and Cuba (Rosset, 1997); and biological control in the context of the philosophy of agriculture and global resources (Altieri et al., 1997).

The context for biological control is often not considered by those who challenge the process. Scientists trained in biological control do not propose introduction of primary landscape-changing organisms; this has already been done, deliberately, accidentally, or naively, and these invasive species are estimated to cost over $\$ 122$ billion per year in the United States (Pimentel, 2002). Biological control scientists propose introduction of host-specific natural enemies of pests, after careful study, risk assessment, and prediction/anticipation of likely consequences, to solve severe and increasing damaging ecological and economic problems. Many citizens and stakeholder groups (e.g., Callahan, 1999) choose biological control of many of these invasive species over other pest management strategies, accepting the small risk involved. 
Some biological control scientists have been surprised at the vehemence with which biological control has been challenged (Hamilton, 2000; Howarth, 1991; Louda et al., 1997, 2003; Miller and Aplet, 1993; Pearson and Callaway, 2003; Simberloff, 1992; Simberloff and Stiling, 1996; Stolzenburg, 1999; Strong, 1997). After all, many argue, biological control is the "white hat" of applied ecology. For example, only eight of $350+$ weed biological control agents have caused any recorded nontarget damage in 130 years of work (Waterhouse, 1999). It is interesting to note that it is usually people who are not trained in biological control, and who do not own or manage land degraded by invasive species, who are most critical of biological control.

Many biological control scientists feel that regulators are slow to adopt changes in regulations and procedures, and do not always base their decisions on the best available science (Delfosse, 2004; Sheppard et al., 2003). This criticism must be placed in context. Globally, regulators are often hindered by having to regulate biological control by suites of laws passed for other reasons, many of which were passed early- to mid-last century.

At a time when biological control is needed more than ever, this is certainly a challenging context in which to practice biological control! I discuss below some of the current ethical challenges.

\subsection{Post-release monitoring}

It is unethical to release biological control agents without monitoring their impacts on target and closely related nontarget species. Post-release monitoring, however, has been the most neglected part of biological control programs, particularly in the United States, due to political, financial, and philosophical constraints. Potential nontarget species in the area of release should be identified, and studied along with the target species (e.g. Denslow and D'Antonio, 2005; Dudley and Kazmer, 2005). Where monitoring is a major feature of biological control programs, refutable hypotheses are tested, and much is learned about interactions of natural enemies, targets and the systems in which they operate.

The U.S. Department of Agriculture, Agricultural Research Service (USDA-ARS) has recently changed its biological control of weeds policy (Delfosse, 2000), implementing five key points:

1. each project is considered to last at least 20 years, although individual components may take only 3-5 years, and a long-term strategic plan will be prepared for each new target species;

2. post-release monitoring on the target is required;

3. potential nontarget species (identified through hostspecificity test results and other ecological procedures) in the area of release will be identified, and potential impacts will be studied on them as for the target species;

4. cultural control/revegetation will be considered wherever possible and appropriate, to increase stress on the weed population and maximize the likelihood that beneficial flora rather than weeds is the outcome; and

5. partnerships will be sought to increase technology transfer and to ensure that research areas in which ARS does not have expertise (e.g., potential impacts on birds, as with the Tamarix program; DeLoach et al., 2000) are included.

\subsection{Revenge effects}

Mertin (1936) introduced the term unanticipated consequences of actions. Tenner (1997) changed the phrase to unintended consequences of technology and science. Predictability is critical to this process and has resulted in an anticipation of revenge effects. Some ecologists argue that we cannot predict the consequences of introduction of biological control agents. Further, if we cannot predict likely consequences, we should not make introductions of biological control agents. However, 130 years of biological control of weeds research indicates clearly that we can make projections of present trends vis-à-vis consequences with a high degree of certainty (McFadyen, 1998; Wapshere et al., 1989; Waterhouse, 1999).

The discussion of "after this, because of this" (see the discussion on causality, above) should be kept in mind. Ecological systems do not deal in one cause leading to one effect forever, because "we can never do merely one thing" (Hardin, 1998).

Biological control researchers must continue to develop and improve host-specificity testing protocols to improve the prediction of the ecological host range by physiological host-specificity testing (e.g., Briese, 2005; Delfosse, 2000; Sheppard et al., 2005), including using $\mathrm{f}_{1}$ sterility and expert systems.

\subsection{Conflict-of-interest in biological control}

Conflict-of-interest in biological control arises from three main categories (Cullen and Delfosse, 1985): choice of targets for biological control programs; choice of biological control agents for targets; and resource allocation decisions (e.g., chemical vs. biological). In the most intense conflict, that over biological control of E. plantagineum in Australia (Cullen and Delfosse, 1985), a legal injunction held up the program for over 8.5 years. McFadyen (1998) presented several other cases of conflict-of-interest in biological control. The key issue is that biological control scientists have led the way in identifying and resolving these conflicts, and this should and will continue.

\subsection{The "do-nothing" response}

The positive direct and indirect effects from biological control are often omitted or downplayed in discussions of risk from a biological control agent, and it is sometimes proposed that we should "do nothing" until complete information is at hand. Incomplete information complicates 
objective estimates of risk because the nature and extent of actual risk is not understood, so the subjective valuation of risk is biased, and usually overstated. However, the "donothing" option also has risks, and is unrealistic and dangerous, because nothing never happens (Hardin, 1998). Thus, there can be an equal or greater risk to nontarget species from not using biological control as the base strategy of IPM.

However, it is difficult to isolate the exclusive impact of potential risk by agents on nontarget species. Environmental factors other than natural enemies influence risk, and if omitted, bias (overestimate) estimates of risk due to biological control. A complete risk analysis of the alternatives can help decide if biological control should be used for a given pest situation.

\section{Case history: biological control of nodding thistle, Carduus nutans}

Rhinocyllus conicus is a Eurasian weevil that has been introduced into North America for biological control of thistles (Julien and Griffiths, 1999). Found during surveys in the 1960 s, it was the primary potential biological control agent for invasive Carduus spp. weeds. $R$. conicus was extensively tested for host-specificity, starting in the early 1960s (and subsequently), and has been approved for release in five countries where Carduus spp. are weeds (Julien and Griffiths, 1999). Adults feed on stems and foliage and oviposit in capitula, and larvae feed internally on the receptacle.

The risk assessment process for $R$. conicus was remarkably complete, especially considering that the host-specificity testing was completed 32 years ago. $R$. conicus was found to be extremely specific to a small group of closely related Carduine Eurasian thistles, primarily Carduus and Cirsium. Cirsium has native North American and introduced Eurasian species; some native and all introduced species are weedy.

Application for release of $R$. conicus was submitted to a Federal-State review committee in 1967. It was clearly stated that both native and introduced Cirsium spp. were likely to support development of $R$. conicus (Schroeder, 1980; Zwölfer, 1967; Zwölfer and Harris, 1984). The release proposal was extensively peer reviewed by Federal, State, and international colleagues: USDA-ARS, USDA-Forest Service, U.S. Department of Interior (Bureau of Reclamation, Bureau of Land Management and Fish and Wildlife Service), and Canada. It was unanimously agreed to accept the risk to native Cirsium spp. given the potential to help manage Carduus, a major weed. Thus, as is their responsibility, the reviewers recommended release of $R$. conicus on behalf of society at large.

Following release, $R$. conicus established readily, spread by itself, and was also redistributed widely by cooperators . $R$. conicus severely impacted Carduus thistles and contributes significantly to their management. Impact on native Cirsium spp. has been detected (Louda et al., 1997), as was predicted in the 1960s (Boldt, 1997). Of course, being able to predict the precise magnitude or extent of nontarget damage is not possible or needed, and if this became a requirement, it would stop biological control, as well as a lot of other field research.

What does the risk analysis process contribute to this example? From the host-specificity testing it was known and communicated that there is a qualitative risk that native and introduced Cirsium spp. may be attacked at a given field site. There is a phenology of events that must occur for the attack to be significant, and for the native Cirsium population to be placed at risk. Although the risk assessment process starts with attack by a single weevil on a single plant, it is important to note that it is the population level, not the individual plant level, that is important in such risk assessments.

This attack can be quantified using several agent-based parameters: adult feeding on plant parts, oviposition, eclosion, larval feeding, pupation; emergence, additional adult feeding, mating, etc., with each parameter having sublevels that must be met before the next stage in the phenology of attack can be achieved. There is also a similar complex plant phenology that must be matched with the agent phenology for a significant risk to be presented to the plant population Louda et al. (1997) has provided a very valuable start to the analysis of this interaction.

This is an interesting example of changing societal values. Risk and uncertainty have different qualitative meanings at different times (Wilson and Shlyakhter, 1997). For example, potential damage to native Cirsium thistles was accepted when the application for release of the weevil $R$. conicus was made because the native thistles were not valued highly (some are still considered to be native weeds; Boldt, 1997) and the weed (nodding thistle) was a major invasive species. In fact, $R$. conicus has done exactly as the host-specificity testing predicted, but the system is being examined in the light of a new societal value for native thistles (Louda et al., 1997; Stolzenburg, 1999; Strong, 1997). As a result of these changing societal values, biological control is being criticized inappropriately. A key philosophical question arises: is it fair to judge a decision that was reasonable at some time in the past on society's current standards? Also, what other changes in the complex ecological systems in which the Carduus-Cirsium-Rhinocyllus systems operate have occurred over the last three decades that may affect the outcome ("absence of evidence ..." and "after this, because of this")?

\section{Summary and future challenges and opportunities for success}

There are a number of things that biological control scientists can continue to do to ensure that biological control remains the base strategy of integrated pest management, and to quantify, predict, and minimize the risks of its use.

Biological control ethics has not often been discussed per $s e$ in the context of programs. However, biological control 
scientists have always made conscious ethical decisions when it comes to testing and releasing natural enemies. This is perhaps more obvious and visible with biological control of weeds because of the long history of host-specificity testing, but such testing for natural enemies used for biological control of arthropod pests is increasing, and scientists are communicating this information (e.g., Van Lenteren et al., 2003). For example, lists of species to be tested against a natural enemy are carefully prepared considering both target and potential nontarget species. When a natural enemy is proposed for release after such testing, it is based on an examination of the data collected during the risk assessment (host-specificity testing and a prediction of the likely ecological host range). If a scientist cannot reach an ethical decision that a natural enemy would be both safe and efficacious (i.e., "acceptable risk" is not demonstrated), then a petition for release is not submitted to a regulatory agency. Many natural enemies that a scientist feels would be safe and efficacious are not proposed for release because the ethical test of acceptable safety cannot be demonstrated by testing. Sometimes additional experimentation is conducted which produces data that allow a scientist to reach the conclusion that the ethical standard of safety is reached. If the data do not allow such a conclusion, the natural enemy is dropped from consideration. Thus, when a natural enemy is proposed for release, it is concurrence by regulatory agencies of an ethical decision by a scientist that is sought. In short, every decision to propose release of a natural enemy is an ethical decision made by the scientist, based on a careful, exhaustive examination of the best available data.

Conflicts and risks of introduction of biological control agents should be acknowledged and resolved, without acting defensively. Biological control has been practiced for over 130 years with minimal nontarget damage, and acceptable risk to most customers and stakeholders. Many pests have been managed with biological control, although these successes can become "invisible" and are not always appreciated or even known by people who do not have to deal with the target pest as a problem. At a minimum, risk analysis and $B C A$ should be standard procedures for future biological control programs.

The science base of biological control can be increased by developing and testing refutable hypotheses, and by ensuring that monitoring and evaluation on the target species and on potential nontarget species is the key postrelease activity. This will help us to understand and communicate the predictability of host range ("physiological" vs. "ecological").

Input from environmental groups and other customers and stakeholders should be welcomed. Trained biological control scientists should continue to lead the way in technology transfer of biological control products and agents, but not prematurely. The tendency by action agencies (State and Federal regulatory or land management agencies) to rush to distribute agents as widely and quickly as possible has ruined more than one long-term monitoring research site. Closer coordination between research and action agencies is imperative. Similarly, there are also tremendous opportunities for the augmentative biological control industry that are not yet fully developed, and biological control scientists should continue to work with industry to ensure their early and meaningful involvement to risk analysis in program development. Biological control scientists should also continue to take a major role in identifying habitat loss, invading species, and sustainable solutions to these problems.

In short, the atmosphere surrounding biological control is increasingly one of challenge, and it is likely that these challenges will increase over time (Delfosse, 2004). Therefore, for biological control to remain a viable strategy in this new Century, trained biological control scientists must change the way they plan, implement, transfer and evaluate research. New laws and regulations must be passed that facilitate the release of safe biological control agents; regulators should be facilitators and not gatekeepers. Partnerships with customers and stakeholders of biological control must increase. One definition of insanity is continuing to do something in the same way, and expecting a different outcome. Let's hope that sanity rules in the new millennium.

\section{References}

Ahl, S.S., Acree, J.A., Gibson, P.S., McDowell, R.M., Miller, L., McElvaine, M.D., 1993. Standardization of nomenclature for animal health risk analysis. Revue Scientifique et Technique de l'Office International des Epizooties 12, 1045.

Altieri, M.A., Rosset, P.M., Nicholls, C.I., 1997. Biological control and agricultural modernization: towards resolution of some contradictions. Agric. Human Values 14, 303-310.

Andersen, M.C., Ewald, M., Northcott, J., 2005. Risk analysis and management decisions for weed biological control agents: ecological theory and modeling results, Biol. Control 35, 330-337.

Anderson, P., 2004. Absence of evidence is not evidence of absence. Br. Med. J. 328, 476-477.

APHIS (Animal and Plant Health Inspection Service), 2000. Plant Pest Permits. U.S. Department of Agriculture, APHIS, <http:// www.aphis.usda.gov/ppq/>.

AQIS (Australian Quarantine and Inspection Service), 2000. Requirements for importing biological control agents for weeds and invertebrates. Agriculture, Fisheries and Forestry-Australia, <http:// www.aqis.gov.au/docs/appolicy/bcontrol.htm>.

Barratt B., I., P., Moeed, A., 2005. Environmental safety of biological control: policy and practice in New Zealand, Biol. Control 35, 247-252.

Bentley, J.W., O'Neil, R.J., 1997. On the ethics of biological control of insect pests. Agric. Human Values 14, 283-289.

Bier, V.M., 1997. An overview of probabilistic risk analysis for complex engineered systems. In: Molak, V. (Ed.), Fundamentals of Risk Analysis and Risk Management. Irwin Press, Chicago, IL, pp. 67-85.

Boldt, P.E., 1997. Response of a Rhinocyllus researcher. Biocontr. News and Info 18, 100.

Briese, D.T., 2005. Translating host-specificity test results into the real world: the need to harmonise the yin and yang of current testing procedures. Biol. Control 35, 208-214.

Callahan, M., 1999. Innovative weed fighting ideas. American Small Farm $8,16-17$.

Callan, S.J., Thomas, J.M., 1996. Environmental Economics and Management. Irwin Press, Chicago. 
Cooke, R.M., 1991. Experts in Uncertainty: Opinion and Subjective Probability in Science. Oxford University Press, Oxford, UK. p. 334.

Cullen, J.M., Delfosse, E.S., 1985. Echium plantagineum: catalyst for conflict and change in Australia. In: Delfosse, E.S. (Ed.), Proceedings of the VI International Symposium on Biological Control of Weeds, 1925 August 1984, Vancouver, British Columbia. Agriculture Canada, Ottawa, pp. 249-292.

Davis, J.C., 1996. Comparing Environmental Risks: Tools for Setting Government Priorities. Resources for the future, Washington, DC.

DeBach, P., 1974. Biological Control by Natural Enemies. Cambridge University Press, New York, NY, p. 323.

DeBach, P., Rosen, D., 1991. Biological Control by Natural Enemies, second ed., Cambridge University Press, Cambridge, UK. p. 440.

Delfosse, E.S., 1990. Biological control and the cane toad syndrome. Aust. Nat. Hist. 23, 480-489.

Delfosse, E.S., 2000. Biological control: important tool for managing invasive species. Agric. Res. 48, 2.

Delfosse, E.S., 2003. Overview of the ecological risk analysis process. In: Gottschalk, K.W. (Ed.), Proceedings of the 14th USDA Interagency Research Forum on Gypsy Moth and Other Invasive Species. USDA Forest Service North Eastern Research Station, General Technical Report NE-315, p. 17.

Delfosse, E.S., 2004. Introduction. In: Coombs, E.M., Clark, J.K., Piper, G.L., Cofrancesco, Jr., A.F. (Eds.), Biological Control of Invasive Plants in the United States. Oregon State University Press, Corvallis OR, pp. 1-11.

Delfosse, E.S., Lewis, R.C., Hasan, S., 1995. Release of Uromyces heliotropii in Australia: a key agent in the integrated pest management system for common heliotrope. In: Delfosse, E.S., Scott, R.R. (Eds.), Proceedings of the VIII International Symposium on Biological Control of Weeds. 2-7 February 1992, Lincoln University, Canterbury, New Zealand. DSIR/CSIRO, Melbourne, pp. 329-336.

DeLoach, C.J., Carruthers, R.I., Lovich, J.E., Dudley, T.L., 2000. Ecological interactions in the biological control of saltcedar (Tamarix spp.) in the United States: toward a new understanding. In: Spencer, N.R. (Ed.), Proceedings of the X International Symposium on Biological Control of Weeds. Montana State University Bozeman, Montana, pp. 819-880.

Denslow, J., D’Antonio, C.M., 2005. After biocontrol: assessing indirect effects of insect releases. Biol. Control $\mathrm{xx}, \mathrm{xxx}-\mathrm{xxx}$. (this proceedings).

Duan, J.J., Messing, R.H., 1997. Biological control of fruit flies in Hawaii: factors affecting non-target risk analysis. Agric. Human Values 14, 227-236.

Dudley, T.L., Kazmer, D.J., 2005. Field assessment of the risk posed by Diorhabda elongata, a biocontrol agent for control of saltcedar (Tamarix spp.), to a non-target plant, Frankenia salina. Biol. Control $35,265-275$.

Evans, J.S., Gary, G.M., Sielken Jr., R.L., Smith, A.E., Valdez-Flores, C., Graham, J.D., 1994a. Use of probabilistic expert judgment in uncertainty analysis of carcinogenic potency. Regul. Toxicol. Pharmacol. 20, 15-36.

Evans, J.S., Graham, J.D., Gary, G.M., Sielken Jr., R.L., 1994b. A distributional approach to characterizing low-dose cancer risk. Risk Analysis $14,25-34$.

Gagné, W.C., Howarth, F.G., 1985. Conservation status of endemic Hawaiian Lepidoptera. Proceedings of the 3rd Congress on European Lepidopterology, Cambridge, UK, 1982. Societas Europaca Lepidopterologica, Karlsruhe, Germany, pp. 78-84.

Gibb, H.J., 1991. Epidemiology and cancer risk assessment. In: Molak, V. (Ed.), Fundamentals of Risk Analysis and Risk Management. CRC Press, Boca Raton, FL, pp. 23-31.

Hamilton, G., 2000. When good bugs turn bad. New Scientist, 15 January 2000, 30-33.

Hardin, G., 1998. The Ostrich Factor. Our Population Myopia. Oxford University Press, New York, NY.p. 168.

Hasan, S., Delfosse, E.S., Aracil, E., Lewis, R.C., 1992. Host-specificity of Uromyces heliotropii, a fungal agent for the biological control of common heliotrope (Heliotropium europaeum) in Australia. Ann. Appl. Biol. 121, 697-705.
Hayek, F.A., 1991. Economic Freedom. Blackwell, Oxford, UK. p. 287.

Henrion, M., Fischoff, B., 1986. Assessing uncertainty in physical constraints. Am. J. Physicians 54, 791-797.

Howarth, F.G., 1983. Classical biological control: panacea or Pandora's Box? Proc. Hawaiian Entomol. Soc. 24, 239-244.

Howarth, F.G., 1985. Impacts of alien land arthropods and mollusks on native plants and animals in Hawaii. In: Stone, C.P., Scott, J.M. (Eds.), Hawaii's Terrestrial Ecosystems: Preservation and Management. University of Hawaii Cooperative National Park Resources Study Unit, Honolulu, Hawaii, pp. 149-178.

Howarth, F.G., 1991. Environmental impacts of classical biological control. Annu. Rev. Entomol. 36, 485-509.

Huffaker, C.B., Messenger, P.S. (Eds.), 1976. Theory and Practice of Biological Control. Academic Press, New York.

James, R.R., 1997. Utilizing a social ethic toward the environment in assessing genetically engineered insect-resistance in trees. Agric. Human Values 14, 237-249.

Jennings, B.H., 1997. The killing fields: science and politics at Berkeley, California, USA. Agric. Human Values 14, 259-271.

Jetter, K.M., 2005. Economic framework for decision making in biological control. Biol. Control 35, 348-357.

Julien, M.H., Griffiths, M.W., 1999. Biological Control of Weeds. A World Catalogue of Agents and Their Target Weeds, fourth ed. CAB International Publishing, Wallingford, UK.

Kaplan, S., Garrick, B.J., 1981. On the quantitative definition of risk. Risk Analysis 1, 11-27.

Lackey, R.T., 1994. Ecological risk assessment. Fisheries 19, 14-18.

Lackey, R.T., 1997. Ecological risk analysis. In: Molak, V. (Ed.), Fundamentals of Risk Analysis and Risk Management. CRC Press, Boca Raton, FL, pp. 87-97.

Lockwood, J.A., 1997. Competing values and moral imperatives: an overview of ethical issues in biological control. Agric. Human Values 14, 205-210.

Lonsdale, W.M., Briese, D.T., Cullen, J.M., 2001. Risk analysis and weed biological control. In: Wajnberg, E., Scott, J.K., Quimby, P.C. (Eds.), Evaluating Indirect Ecological Effects of Biological Control. CAB International, Wallingford, UK.

Louda, S.M., Kendall, D., Connor, J., Simberloff, D., 1997. Ecological effects of an insect introduced for the biological control of weeds. Science 277, 1088-1091.

Louda, S.M., Arnett, A.E., Rand, T.A., Russell, F.L., 2003. Invasiveness of some biological control insects and adequacy of their ecological risk assessment and regulation. Conserv. Biol. 17, 73-82.

MacDiarmid, S.C., 1997. Risk analysis, international trade, and animal health. In: Molak, V. (Ed.), Fundamentals of Risk Analysis and Risk Management. CRC Press, Boca Raton, FL, pp. 377-387.

McFadyen, R.E.C., 1998. Biological control of weeds. Annu. Rev. Entomol. 43, 369-393.

Merrell, P., Van Strumm, C., 1990. Negligible risk: premeditated murder? J. Pesticide Reform 10, 20-22.

Mertin, R.K., 1936. The unanticipated consequences of social action. In: Sztompka, P. (Ed.), On Social Structure and Science 1996. University of Chicago Press, Chicago, pp. 173-182.

Miller, M., Aplet, G., 1993. Biological control: a little knowledge is a dangerous thing. Rutgers Law Rev. 45, 285-334.

Molak, V., 1997a. Fundamentals of Risk Analysis and Risk Management. CRC Press, Boca Raton, FL.

Molak, V., 1997b. Introduction and overview. In: Molak, V. (Ed.), Fundamentals of Risk Analysis and Risk Management. CRC Press, Boca Raton, FL, pp. 1-10.

Morgan, M.G., Henrion, M., 1990. Uncertainty: A Guide to Dealing with Uncertainty in Quantitative Risk and Policy Analysis. Cambridge University Press, New York, NY. p. 344.

Morgan, M.G., Keith, D.W., 1995. Subjective judgments by climate experts. Environ. Sci. Technol. 29, 468-476.

Morgan, M.G., Morris, S.C., Henrion, M., Amaral, D.A.L., Rish, W.R., 1984. Technical uncertainty in quantitative policy analysis - a sulfur air pollution example. Risk Analysis 4, 201. 
NAPPO (North American Plant Protection Organization), 2000. Guidelines for Petition for Import and Release of Non-Native Entomophagous Agents for the Biological Control of Pests, <http:// is.aphis.usda.gov/ppq/standards/drafts/bcgl1099.pdf >.

NAS (National Academy of Sciences), 1983. Risk Assessment in the Federal Government: Managing the Process. National Academy Press, Washington, DC.

Pearson, D.E., Callaway, R.M., 2003. Indirect effects of host-specific biological control agents. Trends Ecol. Evol. 18, 456-461.

Pemberton, R.W., 2002. Selection of appropriate future target weeds for biological control. In: Van Driesche, R., Lyon, S., Blossey, B., Hoddle, M., Reardon, R. (Eds.). Biological Control of Invasive Plants in the Eastern United States. USDA Forest Service Publication FHTET2002-04, pp. 375-86.

Pimentel, D. (Ed.), 2002. Biological Invasions: Economic and Environmental Costs of Alien Associated with Non-Indigenous Plant, Animal and Microbe species. CRC Press, Boca Raton, Florida, USA.

Ricard, J.L., Ricard, T.J., 1997. The ethics of biofungicides - a case study: Trichoderma harzianum ATCC 20476 on Elsanta strawberries against Botrytis cinerea (gray mold). Agric. Human Values 14, 251-258.

Rosset, P.M., 1997. Cuba: ethics, biological control, and crisis. Agric. Human Values 14, 291-302.

Rothman, K.J., 1986. Modern Epidemiology, Chapter 2. Little, Brown and Company, Boston, MA

Ruckleshaus, W.D., 1985. Risk, science, and democracy. Issues Sci. Technol. 1, 19-38.

Schroeder, D., 1980. The biological control of thistles. Biocontr. News and Info. 1, 9-26.

Sheppard, A.W., Hill, R., DeClerck-Floate, R.A., McClay, A., Olckers, T., Quimby, P.C., Zimmermann, H.G., 2003. A global review of risk-benefit-cost analysis for the introduction of classical biological control agents against weeds: a crisis in the making? Biocontr. News and Info $24,91 \mathrm{~N}-108 \mathrm{~N}$.

Sheppard, A.W., van Klinken, R., Heard, T., 2005. Scientific advances in the analysis of direct risks of weed biological control agents to nontarget plants. Biol. Control 35, 215-226.

Simberloff, D., 1992. Conservation of pristine habitats and unintended effects of biological control. In: Kauffman, W.C., Nechols, J.R. (Eds.), Selection Criteria and Ecological Consequences of Importing Natural Enemies. Proceedings of the Thomas Say Publications in Entomology, Entomological Society of America, Lanham, Maryland, pp. 103-117.

Simberloff, D., Stiling, P., 1996. How risky is biological control? Ecology 77, 1965-1974.

Smith, A.H., 1995. Bias, bias, everywhere? And not one drop of science? In: Graham, J.D. (Ed.), The Role of Epidemiology in Regulatory Risk Assessment. Elsevier, Amsterdam, pp. 39-43.

Stolzenburg, W., 1999. Double agents. Nat. Conserv. 49, 18-24.

Strong, D.R., 1997. Fear no weevil. Science 277, 1058-1059.

Sutter, G.E., 1993. Ecological Risk Assessment. CRC Lewis Publishers, Boca Raton, Florida.

Swaney, J.A., 1997. The basic economics of risk analysis. In: Molak, V. (Ed.), Fundamentals of Risk Analysis and Risk Management. CRC Press, Boca Raton, FL, pp. 99-121.
Tenner, E., 1997. Why Things Bite Back. Alfred A. Knopf Inc., New York, NY.

Tversky, A., Koehler, D.J., 1994. Support theory: a nonextensional representation of subjective probability. Psychol. Rev. 101, 547-567.

U.S. EPA (Environmental Protection Agency), 1989. Workshop on EPA Guidelines for Human Risk Assessment: Case of Human Evidence. EPA/625/3-90/017, Risk Assessment Forum, Washington, DC.

U.S. EPA (Environmental Protection Agency), 1992. Framework for Ecological Risk Assessment. EPA/630/R-92/001, Risk Assessment Forum, Washington, DC.

Van Driesche, R.G., Bellows Jr., T.S., 1996. Biological Control. Chapman and Hall, New York, NY. p. 539.

Van Driesche, R.G., Hoddle, M., 1997. Should arthropod parasitoids and predators be subject to host range testing when used as biological control agents? Agric. Human Values 14, 211-226.

Van Lenteren, J.C., Babendreier, D., Bigler, F., Burgio, G., Hokkanen, H.M.T., Van Rijn, P.C.J., Thomas, M.B., Tommasini, M.G., Zeng, Q.Q., 2003. Environmental risk assessment of exotic natural enemies used in inundative biological control. BioControl 48, 3-38.

Vose, D., 1997. Monte Carlo risk analysis modeling. In: Molak, V. (Ed.), Fundamentals of Risk Analysis and Risk Management. CRC Press, Boca Raton, FL, pp. 45-66.

Wapshere, A.J., Delfosse, E.S., Cullen, J.M., 1989. Recent developments in biological control of weeds. Invited Review, Crop Protection 8, 227 250.

Waterhouse, D.F., 1999. Foreword. In: Julien, M. H., Griffiths, M.W. (Eds.), Biological Control of Weeds. A World Catalogue of Agents and Their Target Weeds, fourth ed., CABI Publishing, Wallingford, UK, p. vi.

Wilkinson, R., Fitzgerald, G., 1997. Public perceptions of biological control of rabbits in New Zealand: some ethical issues and practical issues. Agric. Human Values 14, 273-282.

Wilson, R., Shlyakhter, A., 1997. Uncertainty and variability in risk analysis. In: Molak, V. (Ed.), Fundamentals of Risk Analysis and Risk Management. CRC Press, Boca Raton, FL, pp. 33-44.

Wilson, R., Crouch, E.A.C., Zeise, L., 1985. Uncertainty in risk assessment. In: Hoel, D.G., Merrill, R.A., Perera, F.P. (Eds.), Risk Quantitation and Regulatory Policy. Banbury Report 19. Cold Spring Harbor Laboratory, New York.

Wright, M.G., Hoffmann, M.P., Kuhar, T.P., Gardner, J., Pitcher, S.A., 2005. Evaluating risks of biological control introductions: a probabilistic risk-assessment approach. Biol. Control 35, 338-347.

Zimmerman, E.C., 1958. Insects of Hawaii, vol. 1. Introduction. University of Hawaii Press, Honolulu.

Zimmerman, E.C., 1978. Insects of Hawaii, vol. 9. Microlepidoptera, Part1. University of Hawaii Press, Honolulu.

Zwölfer, H., 1967. The host-range, distribution and life-history of Rhinocyllus conicus Froel. Progr. Rep., Commonw. Inst. Biol. Contr. No. 18, p. 21.

Zwölfer, H., Harris, P., 1984. Biology and host specificity of Rhinocyllus conicus (Froel.) (Col., Curculionidae), a successful agent for biocontrol of the thistle Carduus nutans L. Zeitschrift für angewandte Entom. 97, $36-62$. 